Cakrawala Dini: Jurnal Pendidikan Anak Usia Dini| p-ISSN2087-I317 | e-ISSN 2621-8321

Vol.1I . No. 2 November 2020 | Hal IID-II6

\title{
UPAYA MENINGKATKAN MINAT MEMBACA ANAK USIA 4-5 TAHUN YANG BERKORELASI DENGAN TRI PUSAT PENDIDIKAN
}

\author{
Agnes Dhear Nur Cahyani ${ }^{1}$, Ainnur Rasydah ${ }^{2}$ \\ ${ }^{1,2}$ Universitas Sebelas Maret Surakarta
}

\begin{abstract}
This scientific article aims to determine the appropriate stimulus in increasing the reading power of children aged 4-5 years at the Islamic Kindergarten Makarima Sukoharjo. This is because according to the results of a UNESCO study entitled "The World's Most Literate Nations" Indonesia is ranked 60th out of 61 countries in the world, which shows that reading habits in Indonesia are very low. This is unfortunate because the ability to read can increase critical thinking power in a person. So, reading habits need to be improved from an early age because at this time children experience rapid growth and development. As well as the need for the role of the Tri Education Center, namely the family environment, school environment, and community environment. To achieve the right stimulation in increasing the reading power of children aged 4-5 years, the Tri Education Center in stimulating children can use a variety of methods or media because early childhood is very easily bored. At Makarima Sukoharjo Islamic Kindergarten, it has been able to answer the problem of reading ability of children aged 4-5 years using group learning models and library centers. The results of this study state that the reading power of children aged 4-5 years at the Islamic Kindergarten Makarima Sukoharjo has been able to master reading skills according to their age developmental stages. This study uses a descriptive qualitative approach with observation and interview methods.
\end{abstract}

Keywords : Children Aged 4-5 Years, Reading Ability, Tri Education Center

\begin{abstract}
Abstrak: Artikel ilmiah ini bertujuan untuk mengetahui stimulus yang tepat dalam meningkatkan daya membaca anak usia 4-5 tahun di TK Islam Makarima Sukoharjo. Dikarenakan menurut hasil studi UNESCO yang berjudul "The World's Most Literate Nations"Indonesia berada di peringkat ke-60 dari 61 negara di dunia yang menunjukkan kebiasaan membaca di Indonesia sangat rendah. Hal ini sangat disayangkan karena kemampuan membaca dapat meningkatkan daya pikir kritis pada seseorang. Maka, kebiasaan membaca perlu ditingkatkan sejak dini karena pada masa ini anak mengalami pertumbuhan dan perkembangan yang pesat. Serta diperlukannya peran dari Tri Pusat Pendidikan yaitu lingkungan keluarga, lingkungan sekolah, dan lingkungan masyarakat. Untuk mencapai stimulasi yang tepat dalam meningkatkan daya membaca anak usia 4-5 tahun maka Tri Pusat Pendidikan dalam menstimulasi anak dapat menggunakan metode atau media yang bervariasi karena anak usia dini sangat mudah merasa bosan. Pada TK Islam Makarima Sukoharjo sudah mampu menjawab permasalahan pada daya membaca anak usia 4-5 tahun dengan menggunakan model pembelajaran kelompok dan sentra perpustakaan. Pada hasil penelitian ini menyatakan bahwa daya membaca anak usia 4-5 tahun di TK Islam Makarima Sukoharjo sudah mampu menguasai kemmapuan membaca sesuai dengan tahapan perkembangan usianya. Penelitian ini menggunakan pendekatan kualitatif deskriptif dengan metode observasi dan wawancara.
\end{abstract}

Kata Kunci: Anak Usia 4-5 Tahun, Kemampuan Membaca, Tri Pusat Pendidikan

'Universitas Sebelas Maret Surakarta, Email: agnesdhear|2国gmail.com

2Universitas Sebelas Maret Surakarta, Email: ainnurrasydah 


\section{PENDAHULUAN}

Menurut Nurhadi (1995:340)

dalam (Husaini, 2020), membaca adalah menangkap makna dari serangkaian simbol-simbol. Definisi membaca menurut Kridalaksan adalah keterampilan mengenal dan memahami tulisan dalam bentuk urutan lambang-lambang grafis dan perubahannya menjadi wicara bermakna dalam bentuk pemahaman diam-diam atau pengujaran keras-keras (Fitra, 2012). Pendapat yang selaras dikemukan oleh Anderson bahwa membaca merupakan suatu proses yang menghubungkan kata-kata tulis (written word) dengan makna bahasa lisan (oral language meaning) yang mencakup pengubahan tulisan atau cetakan menjadi bunyi yang bermakna (Rosyana, 2015). Lebih lanjut Kholid A. H dan Lilis S dalam (Wardani, 2018) mendefinisikan membaca yaitu mengemukakan atau membunyikan rangkaian lambanglambang bahan tulis yang dilihatnya dari huruf menjadi kata, kemudian menjadi frasa, kalimat dan seterusnya. Sedangkan menurut Kamus Besar Bahasa Indonesia(KBBI), membaca adalah mengeja atau melafalkan apa yang tertulis. Oleh karena itu, dapat disimpulkan bahwa membaca adalah suatu proses menghubungkan serangkaian simbol-simbol dan membunyikannya dengan menggunakan bahasa lisan. Menurut hasil penelitian yang dilakukan UNESCO pada tahun 2016 terhadap 61 negara di dunia menunjukkan kebiasaan membaca di Indonesia tergolong sangat rendah. Hasil studi yang dipublikasikan dengan nama "The World's Most Literate Nations" menunjukkan Indonesia berada di peringkat ke-60 (Hutapea, 2019), sehingga sangat penting dilakukannya kegiatan untuk menumbuhkan minat dan kebiasaan membaca di Indonesia. Untuk menumbuhkan minat dan kebiasaan membaca sebaiknya dimulai sejak dini yaitu sejak usia 0-6 tahun. Karena pada masa ini merupakan masa emas atau golden age yang artinya anak mengalami pertumbuhan dan perkembangan yang sangat pesat dan tidak dapat tergantikan di masa mendatang. Hal tersebut didukung oleh Undang-Undang Sisdiknas tahun 2003, anak usia dini adalah anak yang berada pada rentan usia 0-6 tahun. Serta menurut berbagai penelitian di bidang neurologi terbukti bahwa 50\% kecerdasan anak terbentuk dalam kurun waktu 4 tahun pertama.

Pada saat ini, banyak penelitian yang membahas tentang kemampuan dan daya minat anak usia dini dalam hal membaca. Berdasarkan dari hasil penelitian berjudul "Upaya Meningkatkan Minat Membaca Pada Anak Usia Dini” karya (Ikawati, 2013), menjelaskan mengenai cara orang tua dalam meningkatkan minat membaca anak usia dini. Menurut (Ikawati, 2013), upaya dalam meningkatkan minat membaca anak harus dimulai pada ruang lingkup keluarga dan dimulai sejak dini karena minat membaca berpengaruh besar terhadap kesuksesan anak. Maka, orang tua harus membiasakan dan mengarahkan anaknya secara teratur untuk banyak membaca sehingga dalam diri anak akan tumbuh kebiasaan menjadi pembaca dini yang memiliki minat baca alamiah (Ikawati, 2013). Penelitian tersebut sudah sangat bagus dalam hal upaya menciptakan lingkungan keluarga yang dapat membangun minat membaca anak usia dini. Akan tetapi, upaya meningkatkan minat membaca anak usia dini sebaiknya dilakukan sesuai Tri Pusat Pendidikan yaitu lingkungan keluarga, lingkungan sekolah, dan lingkungan masyarakat. Dikarenakan ketiga hal tersebut tidak dapat dipisahkan dan jika dipisahkan kegiatan yang dilakukan akan kurang optimal.

Berdasarkan dari hasil penelitian berjudul "Meningkatkan Kemampuan Mengenal Huruf Melalui Metode Bernyanyi Pada Anak Kelompok A di 
TK Kuncup Mekar Surabaya" karya (Sundari \& Masudah, 2014), menjelaskan mengenai sejauh mana metode bernyanyi dapat meningkatkan kemampuan anak usia 4-5 tahun dalam mengenal huruf. Menurut (Sundari \& Masudah, 2014), metode bernyanyi merupakan suatu cara yang dapat digunakan sebagai penunjang dalam pemberian materi tentang mengenal huruf karena dapat meningkatkan kemampuan mengenal huruf khususnya pada anak usia 4-5 tahun serta harus menggunakan media visual agar hasilnya lebih optimal (Sundari \& Masudah, 2014). Akan tetapi, untuk meningkatkan kemampuan mengenal huruf pada anak usia dini sebaiknya menggunakan metode dan media yang lebih bervariasi agar anak tidak merasa bosan.

Dilihat dari rendahnya minat membaca di Indonesia dan berbagai permasalahan yang masih kurang di beberapa penelitian tentang kemampuan dan minat anak usia dini dalam hal membaca. Penelitian ini dilakukan untuk mengetahui stimulus yang tepat dalam meningkatkan daya membaca anak usia 4-5 tahun di kelompok A TK Islam Makarima Sukoharjo dengan berpedoman pada Tri Pusat Pendidikan. Oleh karena itu, penelitian ini berjudul "Upaya Meningkatkan Minat Membaca Anak Usia 4-5 Tahun Yang Berkorelasi Dengan Tri Pusat Pendidikan”.

\section{METODOLOGI PENELITIAN}

Jenis penelitian yang digunakan pada penelitian ini yaitu penelitian deskriptif menggunakan pendekatan kualitatif dengan metode observasi dan wawancara. Waktu penelitian dilaksanakan bulan November Desember 2019 sebanyak 4 kali di kelompok A (4-5 tahun) kelas zam-zam di TK Islam Makarima, Dusun I, Singopuran, Kartasura, Sukoharjo. Sampel penelitian ini adalah seluruh anak kelompok A kelas zam-zam di TK Islam
Makarima Sukoharjo dengan jumlah 20 anak. Instrumen yang digunakan dalam penelitian ini yaitu lembar penilaian checklist.

\section{HASIL PENELITIAN DAN PEMBAHASAN}

Penelitian ini dilakukan untuk mengetahui kemampuan membaca anak pada kelompok A (4-5 tahun) kelas zamzam di TK Islam Makarima Sukoharjo dan mengetahui upaya apa saja yang dapat dilakukan agar perkembangan membaca anak dapat berkembang sesuai dengan tahapan usia anak. Peneliti menggunakan 3 indikator perkembangan membaca anak usia 4-5 tahun sebagai bahan untuk melakukan penelitian terhadap anak anak kelompok A di TK Islam Makarima Sukoharjo. Indikator pertama : anak mampu menyebutkan 13 gambar yang ada disekitarnya, indikator kedua : anak mampu mengurutkan dan menceritakan gambar yang saling berkaitan, indikator ketiga: anak mampu menghubungkan gambar dengan kata atau kalimat sederhana.

Pada kegiatan indikator pertama, jika anak hanya mampu menyebutkan kurang dari 3 gambar termasuk ke dalam kriteria Belum Berkembang (BB), anak mampu menyebutkan 3-8 gambar termasuk ke dalam kriteria Mulai Berkembang (MB), anak mampu menyebutkan 13 gambar termasuk ke dalam kriteria Berkembang Sesuai Harapan (BSH), dan anak mampu menyebutkan lebih dari 13 gambar yang ada disekitarnya termasuk ke dalam kriteria Berkembang Sangat Baik (BSB). Untuk menstimulasi indikator pertama, guru di kelompok A (4-5 tahun) kelas zam-zam TK Islam Makarima Sukoharjo memberikan kegiatan menyebutkan nama dari beberapa gambar yang dibawakan oleh guru dan benda-benda di dalam kelas, seperti jam dinding, kursi, meja, papan tulis, dsb. Sehingga kosa kata anak akan semakin bertambah, anak menjadi 
lebih mengenal banyak hal, dan anak mampu membaca gambar-gambar tersebut.

Pada kegiatan indikator kedua, jika anak belum mampu merangkai atau menyusun kalimat bahkan menceritakan gambar yang telah disediakan termasuk ke dalam kriteria Belum Berkembang (BB), anak mampu mengungkapkan kata namun masih membutuhkan bantuan dari orang lain untuk menjadi sebuah kalimat termasuk ke dalam kriteria Mulai Berkembang (MB), anak mampu menceritakan gambar secara urut dengan menggunakan kalimat yang sederhana termasuk ke dalam kriteria Berkembang Sesuai Harapan (BSH), dan anak mampu menceritakan gambar secara urut dengan kalimat yang baik dan mampu menceritakannya ke teman-temannya atau orang lain termasuk ke dalam kriteria Berkembang Sangat Baik (BSB). Untuk menstimulasi indikator kedua, guru di kelompok A (4-5 tahun) kelas zam-zam TK Islam Makarima Sukoharjo memberikan kegiatan mengurutkan gambar lalu menceritakan gambar tersebut secara urut. Tetapi sebelumnya guru sudah menceritakan alur beberapa gambar tersebut agar anak dapat mengerti terlebih dahulu tentang gambar-gambar tersebut lalu anak akan mengurutkan gambar-gambar tersebut dan menceritakannya menggunakan bahasanya sendiri.

Pada kegiatan indikator ketiga, jika anak belum mampu menghubungkan satu pun gambar dengan kata termasuk ke dalam kriteria Belum Berkembang (BB), anak mampu menghubungkan minimal 3 gambar dengan kata meskipun masih membutuhkan bantuan dari orang lain termasuk ke dalam kriteria Mulai Berkembang (MB), anak mampu menghubungkan 5 gambar dengan kata tanpa bantuan dari orang lain termasuk ke dalam kriteria Berkembang Sesuai Harapan (BSH), dan anak mampu menghubungkan 5 gambar dengan kata serta mampu membantu temannya termasuk ke dalam kriteria Berkembang Sangat Baik (BSB). Untuk menstimulasi indikator ketiga, guru di kelompok A (45 tahun) kelas zam-zam TK Islam Makarima Sukoharjo memberikan kegiatan menghubungkan dengan garis antara gambar dan kata yang tepat (terdapat 5 gambar panca indra dan 5 kata yang menunjukkan bacaan gambar tersebut). Melalui kegiatan tersebut anak mampu mengetahui dan memahami arti dari gambar-gambar tersebut serta bentuk atau pola tulisannya sehingga kemampuan membaca anak usia 4-5 tahun akan semakin meningkat.

Berdasarkan hasil penelitian, kemampuan membaca pada anak kelompok A kelas zam-zam di TK Islam Makarima Sukoharjo menunjukkan pada indikator 1 terdapat 8 anak yang berada pada kriteria mulai berkembang (MB) dan 12 anak yang berada pada kriteria berkembang sesuai harapan (BSH). Indikator 2 terdapat 13 anak yang berada pada kriteria mulai berkembang (MB) dan 7 anak yang berkembang sesua harapan $(\mathrm{BSH})$. Indikator 3 terdapat 7 anak yang berada pada kriteria mulai berkembang (MB) dan 13 anak yang berada pada kriteria berkembang sesuai harapan (BSH). Jadi, dapat disimpulkan bahwa kemampuan membaca permulaan pada anak kelompok A (4-5 tahun) kelas zam-zam di TK Islam Makarima Sukoharjo sebagian besar sudah mampu menguasai kemampuan membaca sesuai dengan tahapan perkembangan usianya.

Upaya-upaya yang dilakukan

pada TK Islam Makarima Sukoharjo dalam mengembangkan aspek perkembangan bahasa khususnya kemampuan membaca anak usia 4-5 tahun adalah dengan menggunakan model pembelajaran kelompok dan sentra perpustakaan. Di dalam pelaksanaan kegiatan baik dengan model pembelajaran kelompok maupun sentra perpustakaan telah menggunakan 
berbagai metode dan media yang bervariasi dan kreatif.

Menurut (Hasnidah, 2015, hlm. 36), media banyak memberikan dampak positif bagi anak, baik yang berkenaan dengan proses perkembangan otak maupun yang berhubungan dengan kreativitas. Secara umum manfaat media pembelajaran menurut (Zaini \& Dewi, 2017) adalah memperlancar interaksi antara guru dengan anak sehingga kegiatan pembelajaran lebih afektif dan efisien.

Tidak hanya media dan metode yang bervariasi dan kreatif saja, tetapi peranan guru jauh lebih besar dalam meningkatkan minat membaca anak. Peranan tersebut dapat berupa kepedulian guru yang tinggi, pemanfaatan media yang baik dan kreatif serta komunikasi terhadap orang tua. Menurut penelitian dari Jackson menjelaskan bahwa peran yang lebih besar terhadap kemajuan anak-anak di sekolah ialah peranan dari struktur dan organisasi sekolah atau peranan dari guru. Dari hasil penelitiannya mendapatkan hasil bahwa guru memegang peranan penting, dimana perhatian dari guru dapat memajukan perkembangan anak (Jiwa, 2017).

Berdasarkan Tri Pusat Pendidikan yaitu lingkungan keluarga, lingkungan sekolah dan lingkungan masyarakat, sangat berpengaruh terhadap kemampuan dan minat membaca anak. Maka diperlukan dukungan dari lingkungan keluarga dan masyarakat. Hal ini sesuai dengan pendapat (Ikawati, 2013) bahwa rumah adalah tempat yang paling baik untuk memupuk minat membaca. Lingkungan keluarga sangat penting perannya dalam menciptakan minat baca anak anak sedang berkembang pesat pada aspek motorik, emosi, perkembangan sosial, pemahaman terhadap konsep maupun bahasanya, dengan demikian penanaman minat dan kebiasaan membaca pada anak anak sangat besar pengaruhnya. Menurut Thorndike, pentingnya peranan keluarga dalam membaca memiliki kontribusi yang sangat tinggi dalam mempengaruhi terbentuknya minat serta kemahiran membaca pada anak. Dengan orang tua yang gemar membaca akan memacu anaknya untuk menirunya karena anak usia dini merupakan peniru ulung yang sangat baik. Motivasi dan dorongan dalam membacakan dapat ditimbulkan oleh adanya kebiasaan dan contoh dari keluarga. Dapat dilihat dari hasil survei nasional yang dilakukan di Inggris dengan hasil yang menyatakan bahwa 82 persen responden setuju jika anak dapat menumbuhkan minat membaca anak karena didorong olehperan orang tua (Jiwa, 2017). Upaya kegiatan yang dapat dilakukan orang tua guna menstimulus perkembangan membaca anak usia 4-5 tahun adalah dengan melakukan kegiatan menceritakan gambar di waktu tertentu, pemberian contoh membaca yang dapat dilakukan sebelum tidur, menempatkan media yang menarik untuk dibaca (seperti majalah anak, buku cerita anak anak dsb). Menurut (Zaini \& Dewi, 2017), buku cerita bergambar adalah suatu media untuk menyampaikan berbagai pesan dalam bentuk buku yang dikemas dalam tulisan dan gambar. Buku cerita bergambar adalah media yang paling disenangi oleh anak usia dini, karena terdapat banyak ilustrasi (gambar), warna dan cerita sederhana yang dikemas dalam tampilan yang menarik sehingga anak usia dini tertarik membacanya. Serta pemberian nama terhadap benda-benda disekitar anak juga dapat membantu meningkatkan kemampuan membaca anak. Karena dengan adanya pemberian nama atau labelling tersebut maka anak akan mengenal simbol huruf. Yang mana hal tersebut merupakan salah satu kemampuan membaca anak usia dini khususnya anak usia 4-5 tahun.

Lingkungan masyarakat pun memiliki peran yang sangat penting 
terhadap peningkatan kemampuan dan minat membaca anak usia 4-5 tahun. Hal tersebut ditunjukan dengan adanya poster, baliho, simbol simbol lalu lintas dsb dengan begitu akan memunculkan daya pikir kritis anak untuk mengetahui arti atau makna gambar atau tulisan yang ada dilingkungan masyarakat. Karena pada usia 4-5 tahun kemampuan membaca anak masih berada dalam kegiatan membaca gambar.

\section{KESIMPULAN}

Membaca adalah suatu proses menghubungkan serangkaian simbolsimbol dan membunyikannya dengan menggunakan bahasa lisan. Membaca sangat penting untuk meningkatkan daya pikir kritis pada diri seseorang. Maka, untuk membangun minat membaca seseorang sebaiknya sejak dini karena pada masa golden age anak mengalami pertumbuhan dan perkembangan yang sangat pesat sehingga mampu menerima kegiatan yang diberikan dari lingkungannya dengan baik. Upaya meningkatkan minat membaca anak dapat dilakukan dengan media dan metode yang bervariasi serta adanya pendekatan terhadap Tri Pusat Pendidikan yaitu lingkungan keluarga, lingkungan sekolah, dan lingkungan masyarakat. Dengan upaya yang telah dilakukan di kelompok A kelas zam-zam TK Islam Makarima Sukoharjo Sukoharjo maka sebagian besar sudah mencapai indikator kemampuan membaca anak usia 4-5 tahun.

\section{DAFTAR PUSTAKA}

Fitra, E. S. (2012). Peningkatan Kemampuan Membaca Anak Melalui Permainan Melengkapi Huruf Menjadi Kata Taman Kanak-Kanak Al Hikmah Agam. Jurnal Pesona PAUD, 1(1), 13.

Hasnidah. (2015). Media Pembelajaran Kreatif. Luxima Metro Media.
Husaini, I. Z. (2020). Kemampuan Membaca Pemahaman Siswa Kelas VIII SMPN 11 Pujut. Universitas Mataram, 1 (No 1), 1-34.

Hutapea, E. (2019, Juni 23). Literasi Baca Indonesia Rendah, Akses Baca Diduga Jadi Penyebab. Kompas.com.

https://edukasi.kompas.com/read/ 2019/06/23/07015701/literasibaca-indonesia-rendah-aksesbaca-diduga-jadi-penyebab.

Ikawati, E. (2013). Upaya Meningkatkan Minat Membaca pada Anak Usia Dini. Logaritma: Jurnal IAIN Padang, 1(no 02), 1-12.

Jiwa, R. A. P. (2017). Peran Keluarga dan Sekolah Membentuk Literasi Dini dalam Mengembangkan Perilaku Gemar Membaca di Kalangan Anak Prasekolah di Surabaya. Jurnal Universitas Airlangga, 1-20.

Rosyana, D. (2015). Penerapan Strategi DRTA (Directed Reading Thinking Activity) Untuk Meningkatkan Kemampuan Membaca Pemahaman Siswa [Universitas Pendidikan Indonesia]. http://repository.upi.edu/17161/5/ S_BHS\%20A_KDSERANG_110 3957_Chapter2.pdf

Sundari, S., \& Masudah. (2014). Meningkatkan Kemampuan Mengenal Huruf Melalui Metode Bernyanyi Pada Anak Kelompok A Di TK Kuncup Mekar Surabaya. Jurnal Mahasiswa Universitas Negeri Surabaya, 16.

Wardani, K. (2018). Peningkatan Kemampuan Peserta Didik dalam Membaca Dzikir dan Do'a 
Sesudah Shalat Melalui Media Card Sort pada Siswa Kelas IV MI Darul Falah Sumberwono Kecamatan Bangsal Kabupaten Mojokerto. Tasyri': Jurnal Tarbiyah-Syari'ah Islamiyah, 25 (No.1), 88-99.

Zaini, H., \& Dewi, K. (2017). Pentingnya Media Pembelajaran untuk Anak Usia Dini. Raudhatul Athfal: Jurnal Pendidikan Islam Anak Usia Dini, 1 (1), 81-96. https://doi.org/10.19109/ra.v1i1.1 489 